\title{
BANGUN DATA MINING UNTUK RUMAH SEHAT OLEH DINAS KOMINFO DAERAH KOTA TANGERANG
}

\author{
Triyono $^{1}$ \\ Wahyu Hidayat ${ }^{2}$ \\ Purnomo ${ }^{3}$ \\ Dosen STMIK Raharja ${ }^{1,2}$, Mahasiswa STMIK Raharja ${ }^{3}$ \\ e-mail: triyono@raharja.info ${ }^{1}$, wahyu@ raharja.info $^{2}$, purnomo@ @raharja.info $^{3}$
}

\begin{abstract}
ABSTRAKSI
Dinas Komunikasi dan Informatika sakit merupakan salah satu Dinas yang berada di daerah Pemerintahan Kota Tangerang yang memiliki tugas dalam pengembangan aplikasi bagi pemerintah maupun untuk masyarakat. Dinas Komunikasi dan Informatika pada saat ini belum memiliki data bangun untuk rumah sehat, sehingga salah satu Dinas yang dibantu dalam pembuatan aplikasi tersebut adalah Dinas Kesehatan yang saat ini memiliki program rumah sehat yang pendataannya masih bersifat manual sehingga sering terjadi kesulitan dan kesalahan dalam pendataan rumah sehat. Hal ini menyebabkan kurang keefisienannya dalam hal waktu yang ditempuh dalam pendataan dan kurang akuratnya data yang dihasilkan. Selain itu, proses pembuatan laporan dari data rumah sehat masih terdapat kesalahan akibat dari sistem pendataan yang belum tepat. Dalam analisasis pendataan rumah sehat menggunakan metode SWOT untuk mengetahui strategi dan kelemahan pendataan rumah sehat yang digunakan serta melalui beberapa tahapan wawancara dan studi pustaka. Untuk mengatasi masalah yang ada di Dinas Kesehatan, maka diperlukan suatu sistem pendataan rumah sehat yang sesuai dengan kebutuhan, sehingga dapat mengatasi permasalahan pendataan rumah sehat yang terjadi. Hasil pendataan yang dapat secara realti memelalui website sehingga dapat lebih efisien dan akurat hasil yang didapatkan selain itu juga dapat memudahkan pegawai Dinas Kesehatan dalam melihat hasil pendataan rumah sehat pada Kota Tangerang.
\end{abstract}

Kata Kunci: Dinas Kesehatan, Pendataan Rumah Sehat, SWOT

\begin{abstract}
Department of communication and Informatics sick liquid one of the service while in the area of Government of the city of Tangerang who have tasks in application development for the Government or for the community. Department of communication and Informatics at the moment does not yet have the data up for home healthy, so one of the service assisted in the making of such an application is a health service that currently have a healthy home program pendataannya is still the manual nature adversity happens so often and errors in logging of healthy homes. This causes less keefisienannya in terms of the time taken in logging and less akuratnya the resulting data. In addition to that, the process of making data from healthy homes solidify still contained an error logging system of fish that have not been right. In the home logging analisasis healthy using SWOT method to find out the home logging strategies and weaknesses it is used also in healthy as well as through several stages of interview and the study of the literature. For it can make existing problems in the health service, then needed a healthy home logging system to suit your needs, so that it can make the home logging healthy problems that occur. The results of the logging that can be memelalui realti web site so it can be more efficient and Akurát day results obtained in addition it can also make it easier for employees of the Department of health in the home logging results date back healthy in Tangerang.
\end{abstract}

Keywords: Health Services, Home Health, Logging The SWOT 


\section{PENDAHULUAN}

Sistem informasi sangat dibutuhkan pada instansi, khususnya di pemerintahan. Hal tersebut dikarenakan sistem informasi dapat membantu dalam mengerjakan hal yang kompleks selain itu data yang diberikan lebih akurat dan efisien. Sehingga instansi mampu memanfaatkan sumber daya yang ada dalam membantu masyarakat agar menjadi lebih baik. Salah satu contohnya adalah pendaataan rumah sehat. Program rumah sehat merupakan salah satu program yang sedang dijalankan oleh Dinas Kesehatan Kota Tangerang. Dinas Kesehatan Kota Tangerang melakukan pendataan terhadap rumah masyarakat yang didata melalui puskesmas dan posyandu yang berada di Kota Tangerang lalu data akan dimonitoring oleh Dinas Kesehatan. Apabila rumah tidak layak untuk dihuni maka pemerintah akan melakukan bedah rumah.

\section{RUMUSAN MASALAH}

Merancang media informasi dapat dikenal oleh masyarakat menggunakan aplikasi, informasi yang terjadi pada pendataan rumah sehat kota tangerang sehingga Membuat rancang bangun data mining rumah sehat agar pendataan yang dilakukan dapat menjadi lebih efisien dan akurat.

\section{LANDASAN TEORI}

\section{Perancangan Sistem}

Penggambaran dan pembuatan sketsa yang direncanakan dengan kebutuhan pemakai untuk mendapatkan suatu informasi dari beberapa elemen-elemen komputer yang akan menggunakan sistem pemilihan peralatan dan program komputer untuk sistem yang baru.

\section{Pengertian Sistem}

Suatu jaringan kerja dari prosedur-prosedur yang saling berhubungan, berketergantungan dan saling mendukung yang biasanya melibatkan beberapa orang didalam satu atau lebih departemen yang secara keseluruhan bersatu dalam satu kesatuan (Unity) untuk mencapai tujuan tertentu secara efisien dan efektif.

\section{Pengertian Informasi}

Hasil dari pengolahan data yang telah diorganisasi menjadi bentuk yang lebih berguna lagi dan dapat digunakan sebagai alat bantu untuk pengambilan suatu keputusan.

\section{Pengertian Data}

bahan mentah dari fakta-fakta yang dioleh kembali sebagai input dalam menghasilkan suatu informasi.

\section{Pengertian Pendataan}

Kenyataan mengambarkan suatu kejadian kejadian nyata. Yaitu mengumpulkan semua data yang diperlukan, mengolah dan menyajikan data sesui yang diharapkan.

\section{Pengertian Rumah}

Bangunan gedung yang berfungsi sebagai tempat tinggal yang layak huni, Sarana pembinaan keluarga, cerminan harkat dan martabat penghuninya, serta aset bagi pemiliknya.

\section{Rumah Sehat}

Lokasi fisik, kimia dan biologik di dalam rumah, di lingkungan rumah dan perumahan, sehingga memungkinkan penghuni atau masyarakat memperoleh derajat kesehatan yang optimal. 


\section{Tujuan Pendataan Rumah Sehat}

Program yang saat ini sedang berjalan pada Dinas Kesehatan Kota Tangerang bertujuan mendata rumah masyarakat terutama di Daerah Kota Tangerang, Dinas Kesehatan Kota Tangerang melakukan pendataan terhadap rumah masyarakat yang didata melalui puskesmas dan posyandu yang berada di Kota Tangerang dengan beberapa kriteria yang telah ditetapkan oleh Departemen Kesehatan Republik Indonesia lalu hasil pendataan akan diolah oleh Dinas Kesehatan Kota Tangerang.

\section{Konsep Dasar UML (Unified Modeling Language)}

Kumpulan model standar kontruksi dan notasi yang didefinisikan oleh Object Management Group $(\mathrm{OMG})$, yang adalah sebuah organisasi standart untuk pengembangan sistem.

\section{Definisi Prototype}

Model atau simulasi dari semua aspek produk sesungguhnya yang akan dikembangkan, model ini harus bersifat representatif dari produk akhirnya.

\section{Definisi MySQL}

sebuah perangkat lunak sistem manajemen basis data SQL (database management system) atau DBMS yang multithread, multi-user, dengan sekitar 6 juta instalasi di seluruh dunia.

\section{Definisi Framework}

Suatu kerangka kerja dalam aplikasi web yang terdiri atas susunan potongan-potongan program (modul), sehingga programmer tidak perlu membuat kode atau not, karena framework telah menyediakannya."

\section{Use Case Diagram yang diusulkan}

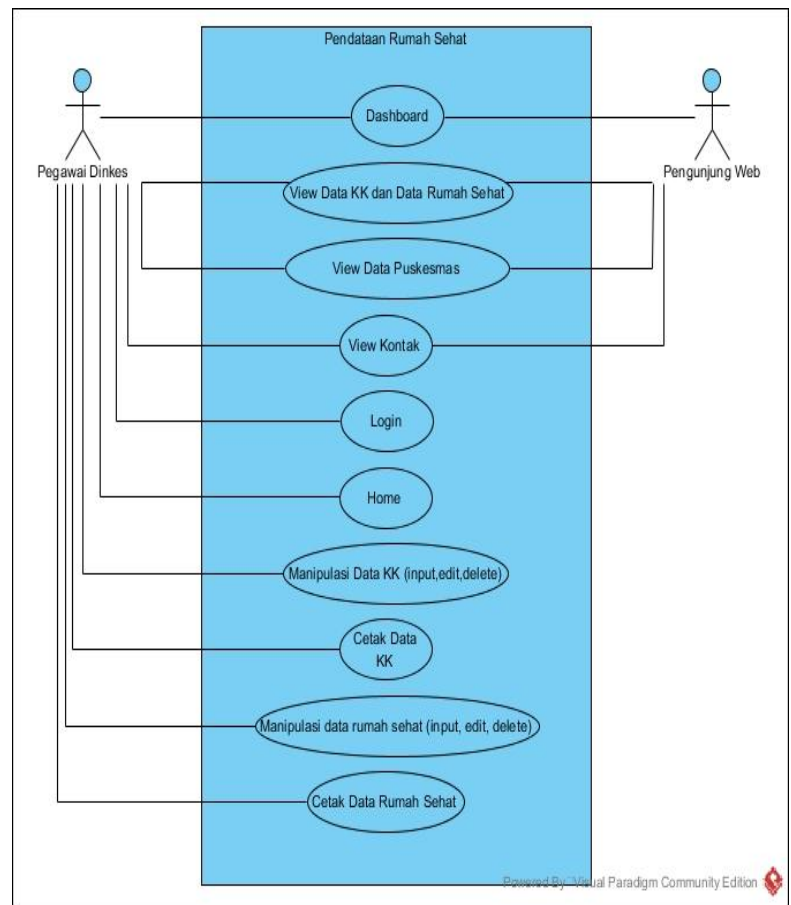

Gambar 1. Use Case Diagram Prosedur Sistem Pendata Rumah Sehat 
Activity Diagram yang Diusulkan

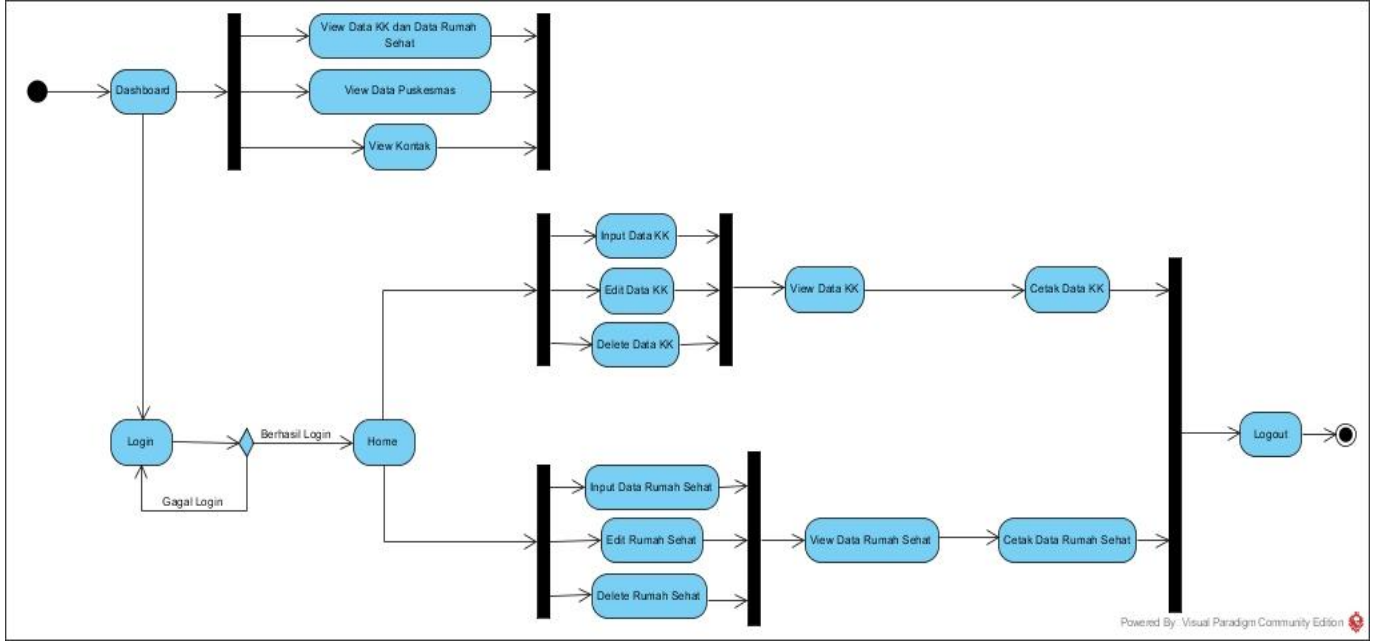

Gambar 2. Activity diagram pada Pegawai Dinkes

\section{Sequence diagram yang diusulkan}

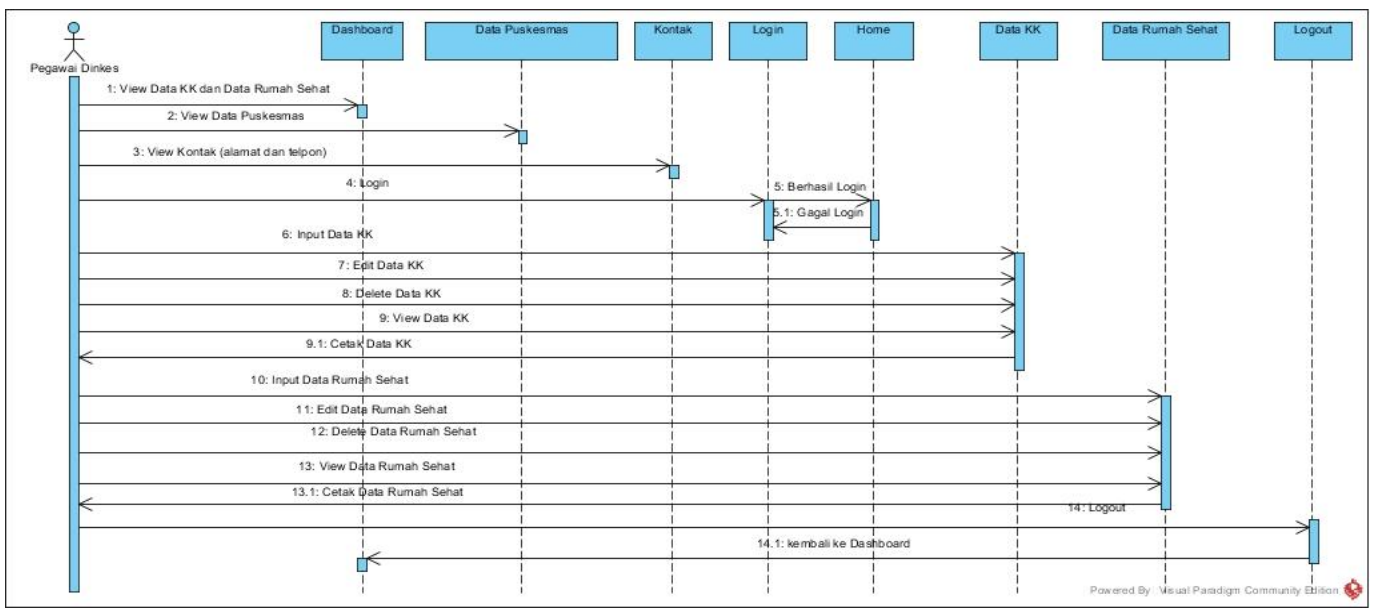

Gambar 3. Sequence Diagram Sistem Pendataan Rumah Sehat Pegawai Dinkes.

\section{Rancangan Program}

a. Tampilan Login

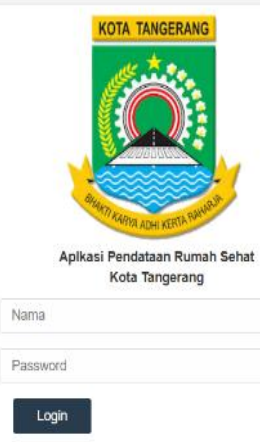

Gambar 4. Tampilan Login 
b. Tampilan Dashboard Data KK dan Data rumah Sehat

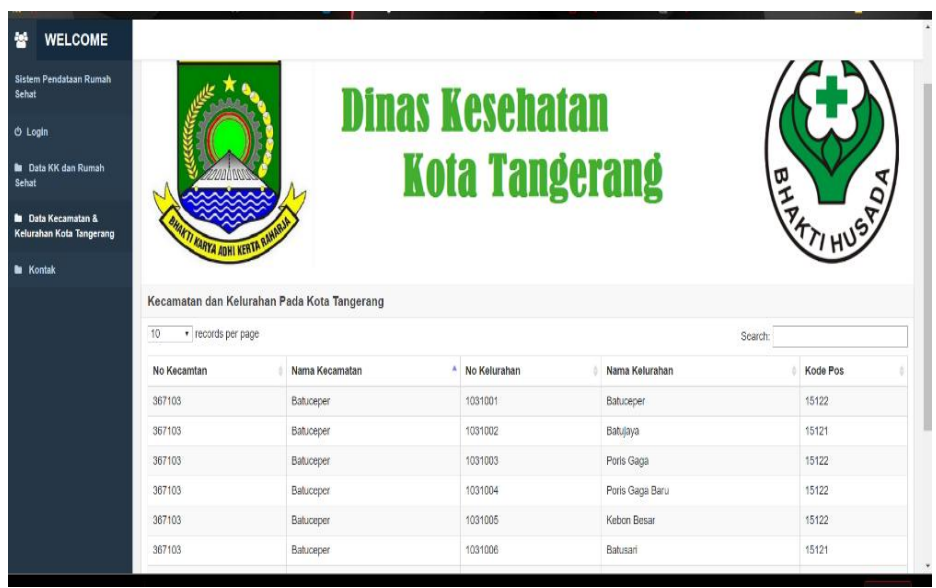

Gambar 5. Tampilan Dashboard Data Kecamtan dan Kelurahan

c. Tampilan Admin

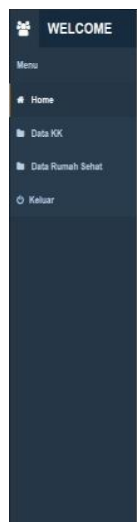

\section{Iota Tangerang}

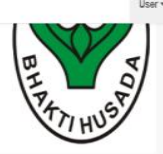

Selamat Datang

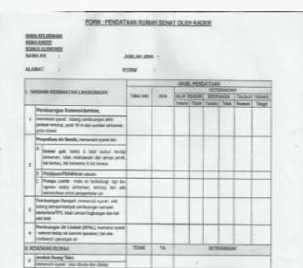

Gambar 6. Tampilan Home Admin

d. Tampilan Data KK Admin

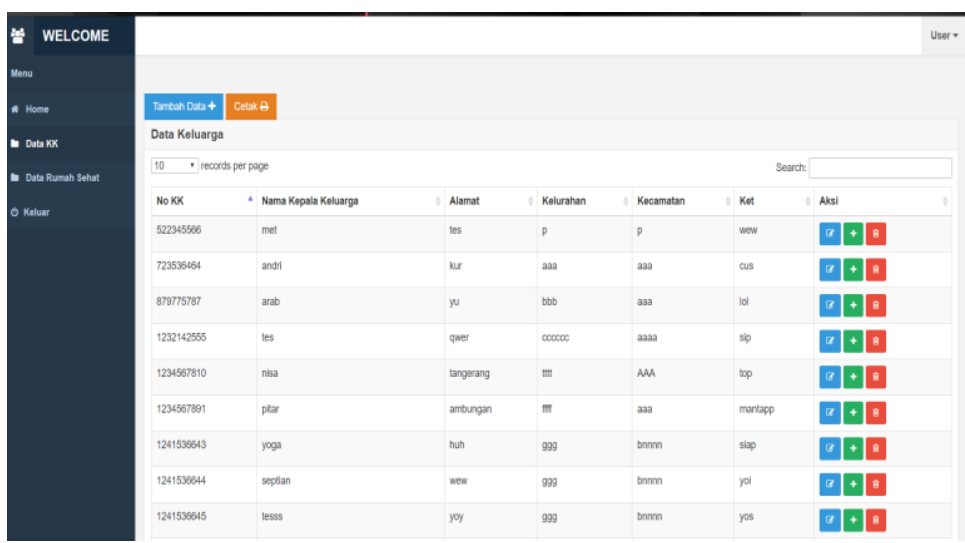

Gambar 7. Tampilan data KK Admin 
e. Tampilan Input Data KK

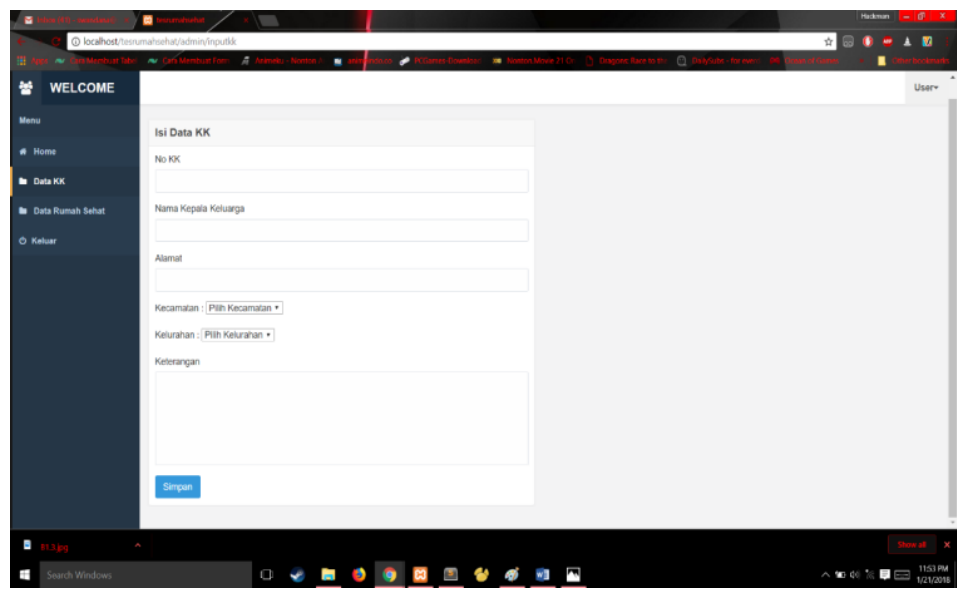

Gambar 8. Tampilan Input Data KK

f. Tampilan Data Rumah Sehat Admin

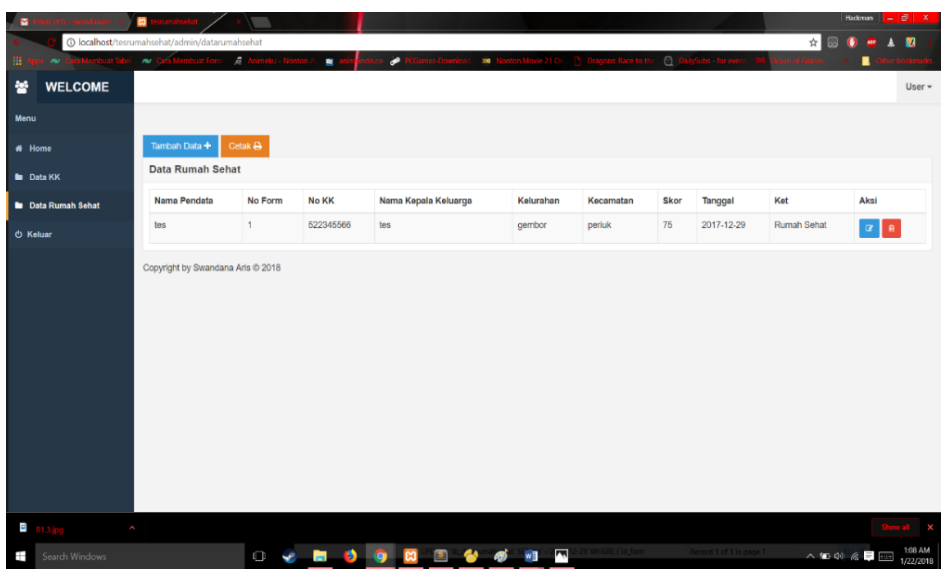

Gambar 9. Tampilan Data rumah Sehat Admin

g. Tampilan Input Data Rumah Sehat

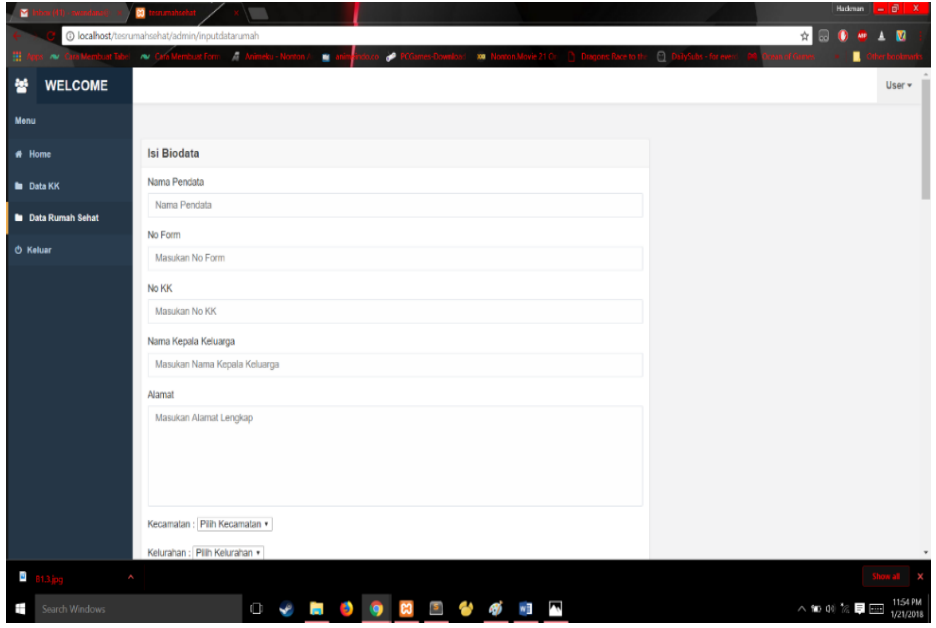

Gambar 10. Tampilan Input Data Rumah Sehat 1 


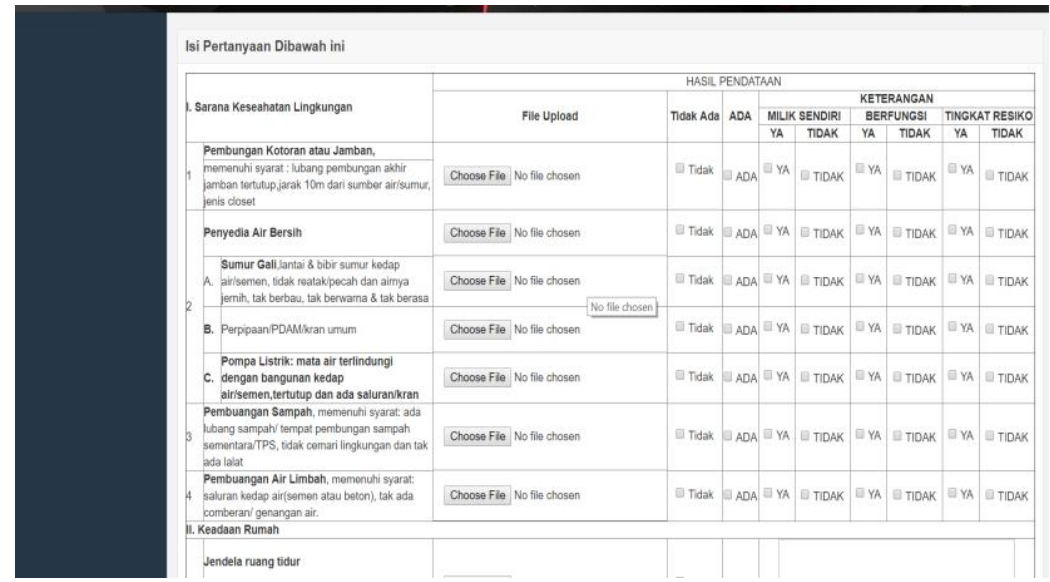

Gambar 11. Tampilan Input Data Rumah Sehat 1

\section{LITERATURE REVIEW}

1. Penelitian yang dilakukan oleh Tri Afriliayanti dan Sri Winiarti yang berjudul "Perancangan Sistem Pendukung Keputusan Penentuan Rumah Sehat" dari penelitain tersebut dapat disimpulkan telah dilakukan analisis kebutuhan sistem unutk mendukung keputusan dalam menetukan rumah sehat dan telah dirancang sebuah sistem yang dapat membantu memberikan saran, masukan atau pertimbangan dalm pengambilan keputusan untuk menetukan kelayakan rumah sehat.

2. Penelitian yang dilakukan oleh Dwi Priyanti dan Siska Iriani yang berjudul "Sistem Informasi Data Penduduk Pada Desa Bogoharjo Kecamatan Ngadirojo Kabupaten Pacitan" dari penelitian tersebut dapat disimpulkan bahwa sistem informasi data penduduk berguna bagi kelancaran di desa Bogoharjo, petugas meras terbantu dalam mencari dan mengelola data data penduduk dan pelayanan didesa Bogoharjo lebih mundah menggunakan sistem informasi data penduduk di bandingkan dengan sistem sebelumnya.

3. Penelitian yang dilakukan oleh Dyah Ayu Mustikowati yang berjudul "Pembangunan Sistem Informasi Pendataan Rumah Tangga Miskin Kecamatan Tulakan Kabupaten Pacitan” dari penelitain tersebut dapat disimpulkan, Kecamatan Tulakan Kabupaten Pacitan belum memanfaatkan komputer secara efektif dalam melaksakan kerjanya khususnya kepala seksi kesejahteraan sosial, contohnya dalam pencatatan data rumah tangga miskin masih dilakukan secara manual, untuk membatu penanganan beban kerja yang dibutuhkan sistem yang terkomputerisasi, dalam hal ini dengan menggunakan sistem informasi rumah tangga miskin, dengan adanya sistem informasi rumah tangga miskin Kecamatan Tulakan maka permasalahan yang sering timbul dapat dikurangi semasimal mungkin. Contoh permasalahanya antara lain data rumah tangga miskin salah satu desa ada yang hilang, pencarian data yang membutuhkan waktu yang lama.

4. Penelitian yang dilakukan oleh Enny Nuraini yang berjudul "Aplikasi Monitoring Pencatatan Data Penjualan Alat Industri Berbasis Mobile Android Pada PT.Phosphatindo Perkasa". Penelitian ini membahas mengenai pemantauan data penjualan secara realtime dari pengguna atau marketing kepada manager sehingga dapat mempermudah manager dalam mengevaluasi dan mengambil keputusan. Metode yang digunakan untuk merancang aplikasi ini diantaranya metode pengumpulan data, analisa, perancangan serta metode pengujian blackbox testing.

5. Penelitian yang dilakukan oleh Dahlan Abdullah dan Cut Ita Erliana yang berjudul "Sistem Informasi Pendataan Kendaraan Hilang Berbasis Web Pada Polres Binjai". Dari penelitian tersenut dapat disimpulkan sistem informasi yang telah dibangun berfungsi mengolah data para pelapor yang kehilangan kendaraan sesuai yang dibutuhkan Polres Binjai. Sistem informasi yang telah dibangun dapat memberikan statistic jumlah kendaraan yang hilang bedasarkan jenis kendaraan sesuai dengan undang-undangyang telah disahkan oleh pemerintahan. Sistem informasi 
yang telah dibangun memberikan kemudahan dalam membaut surat tanda lapor kehilangan. Sistem Informasi yang telah dibangun dapat menentukan persentase dari curanmor yang hilang.Sistem Informasi dapat memberikan laporan sesuai dengan keinginan pihak kepolisian.

6. Penelitian yang dilakukan oleh Mujib Ridwan, Hadi Suyono, dan M. Sarosa yang berjudul penerapan data mining pada "Penerapan Data Mining Untuk Evaluasi Kinerja Akademik Mahasiswa Menggunakan Algoritma Naive Bayes Classifier" dari penelitian tersebut dapat disimpulkan bahwa Pengujian pada data mahasiswa angkatan 2005-2009 mining NBC menghasilkan nilai precision, recall, dan accuracy masing-masing 83\%, 50\%, dan 70\%.Penentuan data training dapat mempengaruhi hasil pengujian, karena pola data training tersebut akan dijadikan sebagai rule untuk menentukan kelas pada data testing. Sehingga besar atau kecilnya prosentase tingkat precision, recall, dan accuracy dipengaruhi juga oleh penentuan data training. Hasil mining NBC dapat digunakan untuk mengklasifikasikan kinerja akademik mahasiswa tahun ke-2 yang dalam penelitian ini dijadikan data target.

7. Mohammed M. Abu Tair, Alaa M. El-Halees , "Mining Educational Data to Improve Students' Performance: A Case Study", In this paper, we gave a case study in the educational data mining. It showed how useful data mining can be used in higher education particularly to improve graduate students' performance. We used graduate students data collected from the college of Science and Technology in Khanyounis. The data include fifteen years period [1993-2007]. We applied data mining techniques to discover knowledge. Particularly we discovered association rules and we sorted the rules using lift metric. Then we used two classification methods which are Rule Induction and Naïve Bayesian classifier to predict the Grade of the graduate student. Also we clustered the students into groups using K-Means clustering algorithm. Finally, we used outlier detection to detect all outliers in the data, two outlier methods are used which are Distance-based Approach and Density-Based Approach. Each one of these tasks can be used to improve the performance of graduate student. Our future work include applying data mining techniques on an expanded data set with more distinctive attributes to get more accurate results. Also, experiments could be done using more data mining techniques such as neural nets, genetic algorithms, k-nearest Neighbor, and others. Finally, the used preprocess and data mining algorithms could be embedded into the college system so that any one using the system can benefited from the data mining techniques.

8. Penelitian yang dilakukan oleh Rizki Wahyuniardi, Bram Andriyanto, Sidik Nurjaman dan Muhammad Yunus yang berjudul "Penyusunan Sistem Informasi Berbasis Web untuk Monitoring dan Evaluasi Sentra IKM Alas Kaki di Cibaduyut - Jawa Barat." Penyusunan Sistem Informasi Berbasis Web untuk Monitoring dan Evaluasi Sentra IKM Alas Kaki di Cibaduyut - Jawa Barat. seminar nasional teknik industri BKSTI 2014. Penelitian ini membahas mengenai sistem informasi ini dapat menjadi alat dalam melakukan monitoring terhadap sentra binaan yang ada di daerahnya. Hasil monitoring ini dapat digunakan sebagai bahan evaluasi instansi pemerintah dalam menyusun program/kegiatan dalam rangka peningkatan kinerja sentra di masa yang akan datang. Metode yang digunakan ialah object oriented dengan pendekatan analisis SWOT.

\section{KESIMPULAN}

Sistem pendataan rumah sehat yang diterapkan oleh Dinas Kesehatan saat ini masih semi manual. Pendataan dilakukan menggunakan form kertas lalu hasil dari pendataan diinput kedalam Miscrosoft Excel. Mempercepat dan menambah akuratnya data yang dihasilkan dalam pendataan rumah sehat peneliti merancang sebuah sistem pendataan rumh sehat yang berbasis website, Pegawai Dinas Kesehatan dapat secara langsung melakukan pendataan dan mencetak hasil pendataan yang telah dilakukan, selain itu peneliti menambkan beberapa fitur yaitu website dapat dikunjungi oleh masyarakat dengan bertujuan memberikan informasi mengenai hasil pendataan yang telah dilakukan oleh Dinas Kesehatan tanpa perlu login terlebih dahulu. 


\section{DAFTAR PUSTAKA}

Afriliyanti, Tri , Sri Winiarti. 2013 "Perancangan Sistem Pendukung Keputusan Penentuan Rumah Sehat" Jurnal Sarjana Teknik Informatika e-ISSN: 2338-5197 Volume 1 Nomor 2, Oktober 2013 Diambil dari : http://journal.uad.ac.id/index.php/JSTIF/article/viewFile/2582/1537 (30 November 2017)

Al-Rosyidn ,Eryan ulana dan Indah Prabawati 2017, Implementasi Peraturan Menteri Perumahan Rakyat Republik Indonesia Nomor 06 Tahun 2013 Tentang Pedoman Pelaksanaan Bantuan Stimulan Perumahan Swadaya Di Kelurahan Mondokan Kecamatan Tuban Kabupaten Tuban. Jurnal E-Journal Unesa Vol 5, No 5.Diambil dari : http://jurnalmahasiswa.unesa.ac.id/index.php/publika/article/view/21048

Andriyanto, Sidik Nurjaman dan Muhammad Yunus. 2014. Penyusunan Sistem Informasi Berbasis Web untuk Monitoring dan Evaluasi Sentra IKM Alas Kaki di Cibaduyut - Jawa Barat. seminar nasional teknik industri BKSTI 2014. Diambil dari : https://www.researchgate.net (23 November 2017)

Anggaeni, Puspita Aritias dan Bambang Sujatmiko. 2013. Sistem Informasi Tugas Akhir Berbasis Web (Studi Kasus D3 Manajemen Informatika Te Ft UNESA). Jurnal Manajemen Informatika. Vol.2, No.2 : 37-45. Diambil : http://jurnalmahasiswa.unesa.ac.id/index.php/jurnal-manajemen informatika/article/view/7383/10028 (15 November 2017)

Aris , Nugroho adi prasetyo, Roslany Bazari Achmad, Yurnelis Defiyan, Daly Sonjaya. 2015. Perancangan Media Pemasaran Berbasis Website Pada PT. Cahaya Terang Mandiri. ISSN : 2302-3805. Diambil dari : http://ojs.amikom.ac.id (27 November 2017)

Badiyanto, S. M.(2013) Buku Pintar Framework Yii. Yogyakarta: Mediakom.

Darmawan, Deni, dan Kunkun Nur Fauzi. 2013. Sistem Informasi Manajemen. Bandung: PT Remaja Rosdakarya.

Depkes RI, 2002, Pedoman Teknis Penilaian Rumah Sehat, Direktorat Jenderal PPM \& PL, Jakarta.

Djahir, Yulia, dan Dewi Pratita. 2015. Bahan Ajar Sistem Informasi Manajemen. Yogyakarta : Deepubish.

Hutahaean, Jeperson. 2015. Konsep Sistem Informasi. Yogyakarta: Deepublish. Kajian Pustaka. 2012. Teori basis data database. Diambil dari : http://www.kajianpustaka.com/2012/10/teoribasis-data-database.html (20November 2017)

Kementerian Kesehatan Republik Indonesia. 2014. Tentang Peta Kesehatan Indonesia Tahun 2010. Diambil dari:http://www.depkes.go.id/resources/download/pusdatin/peta-kesehatan/peta kesehatan-2010.pdf (26 April 2017) 